\title{
Control strategies for bovine dermatophilosis with particular reference to Nigeria \\ ${ }^{1}$ Oyekunle, M.A. and ${ }^{2}$ Talabi, A.O. \\ ${ }^{1}$ Department of Veterinary Microbiology and Parasitology, ${ }^{2}$ Department of Veterinary Medicine and Surgery, College of Veterinary Medicine, Federal University \\ of Agriculture, Abeokuta, Nigeria. \\ E-mail: maoyekunle@yahoo.co.uk
}

\begin{abstract}
Dermatophilosis is an economically important disease prevalent in Nigeria. It is a skin disease that affects mainly cattle, sheep and horses, but also goats, dogs and cats, many wild mammals, reptiles and, occasionally, humans. The disease is caused by the bacterium Dermatophilus congolensis, which is a member of the order Actinomycetales with a great potential for causing severe economic losses in cattle. In recent time, there have been cases of ineffective treatment to this disease in Nigeria. The various control strategies for Dermatophilosis are discussed in this paper. Recommendations for control of Dermatophilosis in Nigeria on short term include ecto-parasite control by regular use of insecticide/acaricide in dips with added $0.03 \%$ copper sulphate or 1\% solution of alum (potassium aluminium sulphate) spray. Infected animals should be isolated and treated with effective antibiotics or culled, while use of barb wire in the construction of cattle paddocks should be discouraged. Adequate nutrition should be provided for the animals all year round. Long term measures include gradual genetic upgrading of susceptible breeds with fairly resistant ones such as N'dama, Muturu and Keteku.
\end{abstract}

Keywords: Dermatophilosis, Cattle, Control, Nigeria

\section{Introduction}

Dermatophilosis, also known as streptothrichosis, is an exudative, pustular dermatitis (OIE Terrestrial Manual 2008) that is widespread in Africa, Asia, South America and the Caribbean and can affect cattle, sheep, goats and horses (Rushton et al., 2002), but also dogs and cats, many wild mammals, reptiles and, occasionally, humans. Dermatophilosis is caused by the bacterium Dermatophilus congolensis, which is a member of the order Actinomycetales (OIE Terrestrial Manual 2008). In Africa, the disease is often combined with Demodicosis to produce 'Senkobo disease', a more severe and often fatal combination (Radostits et al., 2007) which has proved to severely limit the introduction of exotic breeds of cattle
(Rushton et al., 2002).

There is considerable variation in the clinical appearance of the disease and in the affected areas of the body. Typically, infection gives rise to the formation of dense scabs on the skin, but in certain areas, such as the perineum in ruminants and the pastern in horses, moist lesions with thickened, folded skin may occur. In such lesions, relatively thin scabs are found. Where lesions are exposed to prolonged wetting, with or without secondary infection, exudative lesions may be present (OIE Terrestrial Manual 2008). This disease can reduce milk production, draught power output and meat production and also cause fertility problems and damage hides (Rushton et al., 2002).

Factors such as prolonged wetting by rain, 
high humidity, high temperature and various ectoparasites that reduce or permeate the natural barriers of the integument influence the development, prevalence, seasonal incidence and transmission of Dermatophilosis (Radostits et al., 2007). The tick Amblyomma variegatum facilitates the transmission of this disease probably through an effect on the immune system of the host (Rushton et al., 2002).

Scabs characteristically comprise alternating layers of parakeratotic keratinocytes invaded with branching bacterial filaments and infiltrates of neutrophils in serous exudate. This gives a palisaded appearance in stained sections. D. congolensis filaments remain confined to the epidermis and very rarely infect the dermis (OIE Terrestrial Manual 2008).

In treating Dermatophilosis, better results are obtained during dry hot weather and in dry climates. Tetracycline repeated weekly as required, Penicillin streptomycin, Dipping or spraying with 0.2 to $0.5 \%$ zinc sulphate, Quaternary ammonium compounds as hand application to individual lesions. The removal of scabs and exudates prior to topical treatment is recommended when practicable (Radostits et al., 2007). Naxcel or chlorhexidine are also useful in the treatment after external parasite control.

There have been cases of ineffective treatment to this disease in Nigeria (Ogwu et al., 1981), the various control strategies for Dermatophilosis are discussed in this paper and specific recommendations are made for the Nigerian situation.

\section{Dermatophilosis in Cattle}

Lesions occur on the neck, body or back of the udder and may extend over the sides and down the legs and the ventral surface of the body. Skin lesions are usually in different stages of progression. The hairs may be matted together as 'paint brush' lesions; crust or scab formation and accumulations of cutaneous keratinized material forming 'wart like' lesions varying in colour from cream to brown. In the early stages, the crusts are very tenacious and attempts to lift them cause pain. Beneath the crusts, there is a granulation tissue and some pus. In the later stages, the dermatitis heals and the crusts separate from the skin but are held in place by penetrating hairs and are easily removed. The thick scabs of Dermatophilosis are characteristic (Radostits etal., 2007).

Diagnostic techniques include identification of the agent by microscopic observation, culture, immunological or nucleic acid recognition methods and serological tests (OIE Terrestrial Manual 2008).

\section{Epidemiology of Dermatophilosis}

Occurrence: The disease occurs in all areas of the world but can be epizootic in tropical and subtropical areas of the world where it can result in considerable economic loss. Surveys of large numbers of cattle in Africa report prevalence rates approaching 15\% with a $100 \%$ infection rate in some herds at the time of peak seasonal prevalence (Radostits et al., 2007). Dermatophilosis occurs in all ages of cattle, sheep, goats, horses, donkeys and occasionally in deer, pig, camels and wildlife species (Zaria, 1993).

Source of Infection: The major source of infection for outbreaks of clinical disease exists with minor active lesions on the face and feet in otherwise healthy carrier animals, and with infection in scabs still carried in the hair and wool from healed lesions. D. congolensis is not highly invasive and does not normally breach the barriers of healthy skin. Dermatophilus may infect lesions and may be transmitted mechanically by feeding flies to result in 
minor infection on the face and feet (Radostits et al., 2007).

Transmission: The organism that causes Dermatophilosis is found on the skin of diseased animals and also carrier animals that show no signs. It is thought to exist in soil but has not been isolated from the environment. Spread of the disease occurs by direct contact between animals or through exposure to contaminated surroundings (fomites) or by biting insects (vectors), particularly flies and ticks. Factors that break-down the natural protective barriers of the skin such as prolonged wetting by rain, high humidity, and high temperature allow the bacteria to spread (Kahn, 2005).

Environmental, management and host risk factors: Climate is the most important risk factor and in tropical and subtropical regions, the disease has its highest incidence and severity during the humid, high rainfall season. Animals in which the disease regresses are usually re-infected repeatedly in successive wet seasons. The disease in cattle requires disruption of natural skin barriers. However, prolonged wetting of the skin of cattle does not appear to be a major predisposing factor by itself and the seasonal occurrence is associated with a concomitant increase in tick and insect infestation. Also, there are breed differences in susceptibility, the N'dama and Muturu cattle breeds are resistant while Zebu, White Fulani, and European breeds are susceptible (Radostits et al., 2007). For example, a study in Ethiopia found that prevalence of Dermatophilosis was higher in cross bred $(5.5 \%)$ than in indigenous zebu $(0.7 \%)$ cattle, in male cattle $(1.7 \%)$ than in female $(0.8 \%)$, in adults $(1.2 \%)$ than in young $(0.8 \%)$ age groups, in wet $(1.6 \%)$ than in dry season $(0.5 \%)$, and in cattle infested with Amblyomma variegatum tick $(2.7 \%)$ than cattle with no tick infestation
$(0.4 \%)$. The study then indicated that Dermatophilosis is a potential determinant factor for the dairy development strategy and concluded that tick control will reduce the risk of Dermatophilosis (Admassu and Alemu, 2011).

Economic Importance: In Africa the disease in cattle causes great losses and many deaths, and the disease ranks as one of the four major bacteriological diseases with equivalent importance to contagious bovine pleuro-pneumonia and brucellosis. Losses are from direct animal loss, decreased work ability of affected oxen, reproductive failure from vulva infection or infection on the limbs of males preventing mounting, death from starvation of calves and dams with udder infection, loss of animal meat and milk production, and downgrading of hides. Reproductive inefficiency is a common accompaniment in severe cases (Radostits et al., 2007).

\section{Control Strategies for Dermatophilosis}

The treatment of Dermatophilosis remains a matter of great concern because the recurrence of the disease after an initial response to treatment using antibiotics by the parenteral route. In Nigeria, Terramycin long-acting (TLA) was described to be the only drug effective in parenteral treatment of Dermatophilosis (Ilemobade et al., 1979). However, Ogwu et al., (1981) reported that animals treated with TLA became re-infected even after recovering from the disease. Fajimi and Taiwo (2005) reported the proven efficacy of the seed oil of mahogany (Kyaya ivoriensis) against dermatitis associated with mange and Dermatophilosis.

In a study in the Republic of Benin, the use of ointments made with ethanolic extracts of leaves of Senna alata, Lantana camara and Mitracarpus scaber, as topical treatments on chronic crusty or acute 
lesions of Dermatophilosis, induced healing of the disease in the nine infected animals treated without recurrence. This was opposed to what was observed by using oxytetracycline, terramycin long-acting (TLA), or procaine-penicillin, antibiotics commonly used parenterally for the treatment of Dermatophilosis which could not prevent the recurrence of the disease. These ointments, when applied once a day for 8-15 days, provoked the falling off of the crusts after 3-4 days of treatment. Hair grew on the treated areas, which healed without scarring, within 3-4 weeks after the end of the treatment. The healed animals became free of Dermatophilosis without recurrence for more than 3 years and were in good health (Ali-Emmanuel et al., 2003). In Bangladesh, long acting Oxytetracycline (Renamycin-LA ${ }^{\circledR}$ injection, Renata Animal Health) along with topical use of $1 \%$ Alum (Potassium Aluminium Hydroxide) was found to be effective in the therapeutic management of Dermatophilosis in the field condition (Nath et al., 2010).

In Egypt, treatment of bovine Dermatophilosis using 2 doses of oxytetracycline /LA with one day apart revealed $85.7 \%$ cure rates, whereas using single dose of oxytetracycline/LA revealed $71.4 \%$ cure rates. Butox ${ }^{\circledR}$ was sprayed once weekly to control infestation with ticks and lice during the period of treatment trial. Butox ${ }^{\circledR} 50$ (Intervet, Egypt), each 100 $\mathrm{ml}$ contain $5 \mathrm{gm}$ Deltamethrin. For spraying for ticks each $50 \mathrm{ml}$ diluted in 100 litres of water, while for lice each $25 \mathrm{ml}$ diluted in 100 litres of water (Awad et al., 2008).

In tropical areas, parenteral treatment with tetracycline $(5 \mathrm{mg} / \mathrm{kg}$ body weight) repeated weekly as required or long-acting tetracycline $(20 \mathrm{mg} / \mathrm{kg}$ body weight $)$ in one injection or procaine penicillin $(22,000$ $\mathrm{IU} / \mathrm{kg}$ body weight) daily for three days is recommended. This should be used in conjunction with acaricides when ticks are present (Radostits et al., 2007).

\section{References}

Admassu, M. and Alemu, S. 2011. Study on Clinical Bovine Dermatophilosis and its Potential Risk Factors in North Western Ethiopia. International Journal of Animal and Veterinary Advances 3:33-36.

Ali-Emmanuel, N., Moudachirou, M., Akakpo, J.A. and Quetin-Leclercq, J. 2003. Treatment of bovine Dermatophilosis with Senna alata, Lantana camara and Mitracarpus scaber leaf extracts. Journal of Ethnopharmacology 86: 167-171.

Awad, W.S., Nadra-Elwgoud, M.I. Abdou and El-Sayed, A.A 2008. Diagnosis and Treatment of Bovine, Ovine and Equine Dermatophilosis. Journal of Applied Sciences Research, 4(4): 367-374.

Fajimi, A. K. and Taiwo, A. A. 2005. Herbal remedies in animal parasitic diseases in Nigeria: a review. African Journal of Biotechnology 4: 303-307.

Ilemobade, A.A., Gyang, E.O., Bida, S.A. and Oddo, P.B. 1979. Cure of Dermatophilus congolensis infection in cattle by long acting oxytetracycline. Review of Veterinary Science 27: 302-305.

Kahn, C.M. (2005). The Merck Veterinary Manual, 9th edition, Merck \& Co., Inc. Rahway, U.S.A.p. 690-692.

Nath, B.D., Ahasan, M.S., Rahman, M.S., Fazlul Huque, A.K.M. 2010. Prevalence and Therapeutic Management of Bovine Dermatophilosis. Bangladesh Research Publications Journal 4(3): 198-207. Retrieved from http://www.bdresearchpublications.co 
m/admin/journal/upload/09171/09171 .pdf

Ogwu, D., Alhaji, S. and Osori, D.I.K. 1981. Effectiveness of long action terramycin injectable solution in the treatment of streptothricosis in cattle. British Veterinary Journal 137: 585-589.

OIE (Office of International des Epizootics), 2008. Dermatophilosis: A Manual of Diagnostic tests for Terrestrial Animals, 5 ed., Chapter 2.4.10. P 725-728. Office of International des Epizootics, Paris.

Radostits, O.M., Gay, C.C., Hinchcliff, K.W. and Constable, P.D. 2007. Veterinary Medicine: A textbook of the Diseases of Cattle, Sheep, Pigs, Goats and Horses, 10 ed., Saunders Elsevier, Spain. p.1048-1051.

Rushton, J., Pilling, D. and Heffernan,
C.L. 2002. A literature review of livestock diseases and their importance in the lives of poor people. Appendix 7. In 'Perry, B.D., Randolph, T.F., McDermott, J.J., Sones, K.R. and Thornton, P.K. 'Investing in animal health research to alleviate poverty', ILRI (International Livestock Research Institute), Nairobi, Kenya. 148 pp., viewed 7 February 2013, from http://www.ilri.cgiar.org/ InfoServ /Webpub/fulldocs/InvestAnim/Book1 /media/PDF_Appendix/Appendix7.pd f

Zaria, L.T. 1993. Dermatophilus congolensis infection (Dermatophilosis) in animals and man. An update. Comparative Immunology and Microbial Infectious Diseases 16(3): 179-222. 